\title{
Design and Research of Virtual Disassembly System for Aircraft Landing Gear
}

\author{
Tongqiang Liu ${ }^{\mathrm{a}}$, Minye Chen ${ }^{\mathrm{b}}$ and Yuan Wang ${ }^{\mathrm{c}}$ \\ College of Air Transportation, Shanghai University of Engineering and Technology, Shanghai, China \\ aliutongqiang321@126.com, bchenminye08@126.com, c215582847@qq.com
}

Keywords: Landing gear, virtual maintenance, Unity 3D, 3DMAX.

\begin{abstract}
Taking the aircraft landing gear as the research object, using 3DMAX to create the aircraft landing gear model, using Unity 3D engine tool to create a virtual maintenance environment, the development of landing gear virtual disassembly system. Compared with the traditional maintenance, virtual maintenance system can avoid the physical operation risk, break the time and space constraints, can be repeated teaching and training, for reducing costs, improve efficiency and vivid teaching is of great significance.
\end{abstract}

\section{Introduction}

With the development of computer technology, graphic image processing technology and virtual reality technology (VR), virtual maintenance technology has become one of the development trend of modern maintenance technology. The aircraft landing gear is one of the four key components of the aircraft, but also an important bearing parts of the aircraft. It taking off and landing in the process of landing an important role in the safety of landing. The use of virtual reality technology to develop a virtual environment in the simulation of landing gear disassembly and maintenance process, can make people out of the reliance on the landing gear, reduce the use of a large number of maintenance tools to avoid the assembly process due to improper operation caused Of a series of security incidents or due to multiple disassembly caused landing gear disassembly function weakened. The learner can repair the landing gear through the virtual environment, grasp the function of the landing gear, the composition of the parts, the working principle and the actual maintenance method.

In recent years, countries have invested a lot of research on virtual maintenance technology, and have made a series of achievements, but China's virtual disassembly technology research is still in the initial stage, the technology is not mature. In this paper, a virtual disassembly and disassembly system based on Unity3D is proposed. This paper proposes a virtual disassembling landing gear system based on Unity3D research, using the virtual dismantling instead of real tear open outfit. In order to solve the problems, such as physical and expensive, venue restriction, time limitation and cost limitation.

\section{System overall framework design}

The landing gear virtual disassembly system uses Unity 3D technology, combined with 3D modeling software 3DMAX to build the optimized model to achieve the landing gear structure display and disassembly demonstration. First use the maintenance manual to obtain all the parts of the landing gear model, and then use the 3DMAX modeling software to the whole of the landing gear model reconstruction, and then need to map the model, and and save the model to the.fbx format into the resource folder of the Unity 3D. In order to make the virtual assembly display real, you can add the necessary elements of the virtual environment, such as Materials, Main Camera, and Directional Light, to set the relevant attributes and dependencies. Unity3D support Java Script and C \# these two scripting languages, which $\mathrm{C}$ \# the most powerful, so the text using $\mathrm{C}$ \# language for script development and design. After the completion of the construction site to complete the code to complete the landing gear parts display and automatically disassemble the animation demo effect.

Figure 1 is the overall framework of the system design, the system has a total of five-tier structure, namely, metadata model, database, Unity 3D services, application layer and presentation layer. 


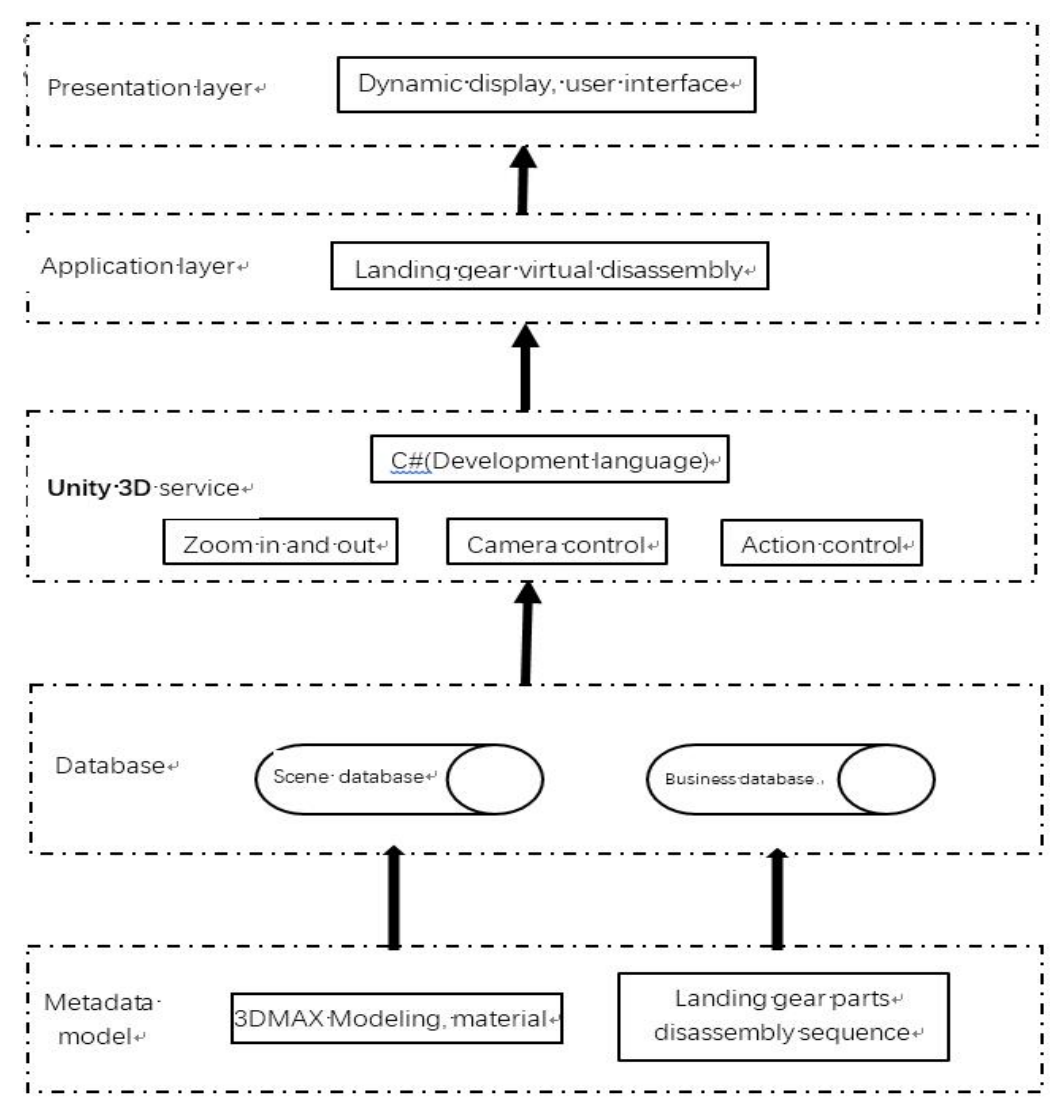

Figure 1 based on Unity 3D landing gear virtual disassembly system

\section{System function design and implementation}

\subsection{DMAX Modeling Process Analysis}

This paper studies the 3d model of the landing gear with 3DMAX modeling software, and uses Photoshop to create a model of the landing gear similar to the prototype. 3DMAX in the geometric modeling, Surface modeling, NURBS modeling and other modeling methods. This modeling uses geometric modeling, through the modification of the basic geometry to get the required shape, and then by combining them together, and then get a complex model. 3DMAX offers a lot of geometric shapes, such as standard geometry, cuboids, cones, cylinders, balls and other basic geometry. The geometry will be converted to editable network, editable patch or editable polygon, adjust its point, side and face, and then add a variety of modifiers to achieve the needs of a variety of shapes.

A landing gear consists of many parts, such as a lock actuator cylinder, closed/opened pillar actuating cylinder, hydraulic brake pipe strut mechanism, damping, shock strut, wheel, etc..

This paper adopts the method of layered modeling, which can be divided into landing gear and landing gear, landing gear wheel and brake system, landing gear turning system. Each system modeling respectively, each layer will need disassembling parts together at the same time, for example: screw tear open outfit, needs to be the same on the screw cap body combination together, giving a unified naming, in animation production, the specific modeling chart shown in figure 2, after modeling in unity $3 \mathrm{~d}$ rendering as shown in figure 3. 


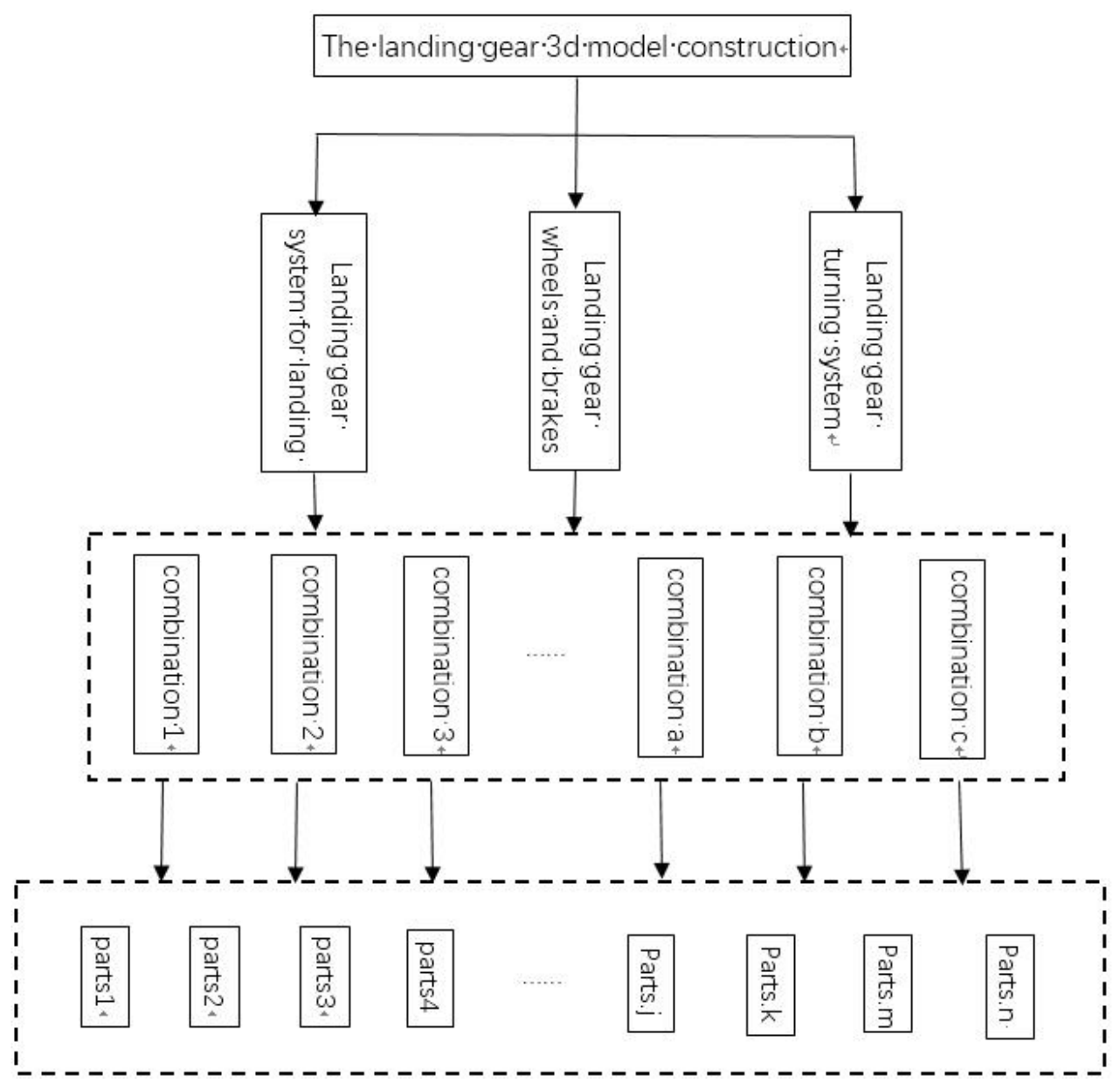

Figure 2 modeling structure diagram

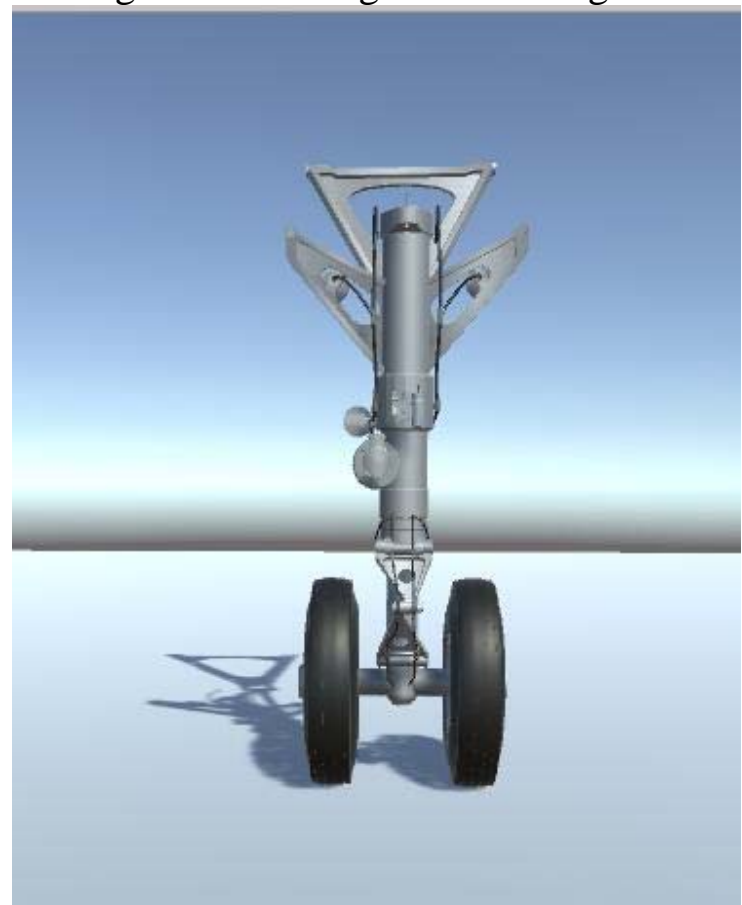

Figure 3 landing gear three-dimensional modeling effect map

\subsection{Design and Implementation of Landing Gear Dismantling System}

Virtual assembly technology has become a model of digital manufacturing technology in the manufacturing industry. For complex products, this technology can optimize product design, avoid or reduce the production of physical models, shorten the development cycle and reduce costs, so as to achieve product parallel development , Improve the quality and efficiency of assembly, improve product after-sales service. This article is based on the shape characteristics of the product, the accuracy of the 
characteristics of a real simulation landing gear assembly process, and allows users to interactively control the landing gear simulation assembly process. In this system, the Unity3D engine is used as a platform to introduce the three-dimensional model of the landing gear.We will build a good three-dimensional landing gear model and landing gear disassembly sequence database into the maintenance database, and use the $\mathrm{C} \#$ script to control the movement of the three-dimensional model of the landing gear, the disassembly of the parts and the switching of the angle to simulate the real Of the disassembly process. Implementation block diagram shown in Figure 4.

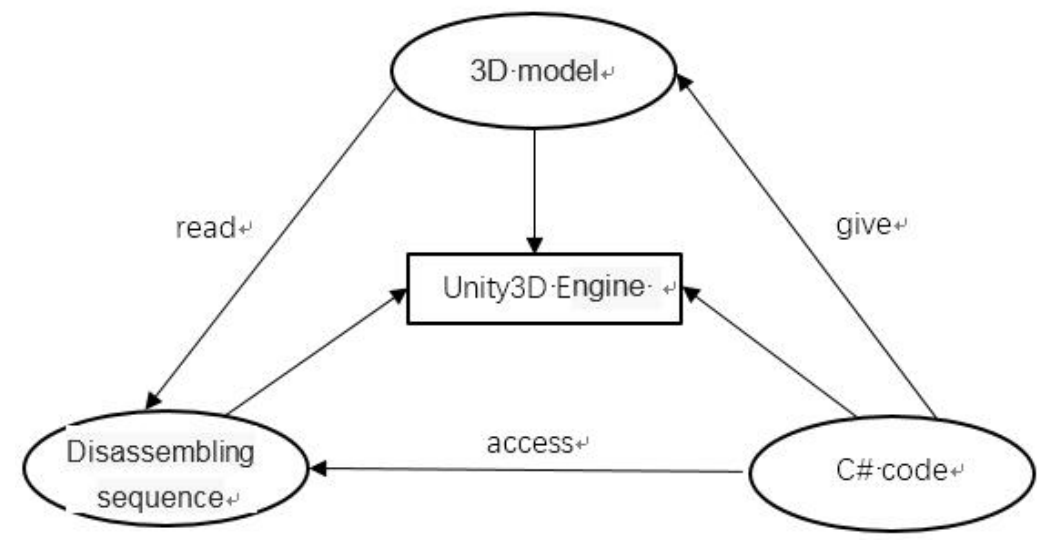

Figure 4 disassembly implementation block diagram

\subsection{The realization of the function of dismantling action animation}

Landing gear disassembly animation is the use of Unity3D engine plug-in iTween function to achieve, iTween core is the numerical interpolation, simply to iTween two values (start value, the end value), it will automatically generate some intermediate value. The movement of the landing gear part is carried out using the iTween.Position function. The position of the position before and after the movement is set in the script. It is used to simulate the trajectory of the landing gear. In order to simulate the actual disassembly effect, the trajectory of the landing gear part is set to the gravitational acceleration trajectory. The script is used to adjust the gameobject.active to achieve the disappearance of the part after the completion of the trajectory. At this point you can simulate the landing gear parts in the process of disassembly animation.

\subsection{The realization of human-computer interaction}

Man-machine interaction control that the landing gear parts disassembly control, is the use of UI interface set Button control, with a Button control a component of the demolition and decomposition, using Unity3D comes with OnClick () function control landing gear Whether the animation script is executed. The disassembly system can be used to display the touch screen display, the operator can click the corresponding button to control the landing gear disassembly.

\subsection{The realization of orderly disassembly function}

Assembled into a complete landing gear, there must be a lot of parts of the correct combination, to go through a number of procedures to complete. It need to go through a number of disassembly experiments to obtain the best disassembly sequence to obtain the best order of disassembly, processed into a database, import Unity3D engine. Each landing gear part has a corresponding ID in the database. Scripts written in $\mathrm{C}$ \# will control the ID of the landing gear parts that need to be disassembled. The script to give the ID of the model for color processing, click the button for parts disassembly, the model of the color change order is the landing gear parts of the disassembly sequence.

\section{Conclusion}

The landing gear virtual disassembly system is a virtual environment developed with 3D MAX software and Unity 3D engine as a platform. Through the three-dimensional modeling to create the system components, using C \# language script procedures to achieve landing gear parts internal structure of the rotation, zoom function. System interface design to achieve the user interaction with the platform, 
through the iween plug-in to achieve the automatic dismantling of the various systems of animation, with animation effects simulation of the real assembly process. In the virtual maintenance of the system will make teaching easier to operate, easy to understand, easy to grasp, and reduce the cost of assembly process and risk.

\section{Acknowledgements}

Chen Min Ye, male, professor, aircraft maintenance direction, College of Air Transportation, Shanghai University of Engineering and Technology.

\section{References}

[1] Zhang Yu-jun, XING Hui, TANG Hua-jun.Study on Virtual Hand Control Technology in Immersive Virtual Training [J]. Computer Measurement and Control, 2017, (02): 81-84.

[2] Yang Yibin, Li Min, Jie Hongwen. Desktop virtual maintenance training system based on Unity3D [J]. Journal of Computer Applications, 2016, (S2): 125-128.

[3] Wu Xiaofei, Shen Rongwei.Design of training platform for automobile generator based on virtual reality technology [J]. Automotive Engineer, 2016, (11): 17-19.

[4] Wu Xiaofei, Shen Rongwei. Design and research of virtual engine disassembly system for automobile engine [J]. Auto parts, 2016, (09): 46-49.

[5] Wang Wenrun, Wang Yangping, Yong Jiu.Study on Virtual Reality System of Railway Signal Equipment Based on Unity3d [J]. Railway Standard Design, 2016, (08): 144-147.

[6] Li Jie. Based on the Android platform to enhance the reality of the system research and application [D]. Hebei Agricultural University, 2015.

[7] Gao Yunxiu. Smartphone Web page buffer interface on the use of the intention of the user [D]. Jilin University, 2015.

[8] Research on Assembly Sequence Planning Method for Maintenance [D]. Nanjing University of Aeronautics and Astronautics, 2012.

[9] Qi Xinjia. Virtual reality technology in the pressurized water reactor regulator control system application [D]. Chongqing University, 2010.

[10] Zhu Luofeng. Virtual machine maintenance training system and its key technology research [D]. Nanjing University of Aeronautics and Astronautics, 2009.

[11] Dai Yongfeng. Civil aircraft maintenance of virtual analysis and verification methods [D]. Nanjing University of Aeronautics and Astronautics, 2005.

[12] Ma Hongyan. Aircraft landing gear system fault diagnosis simulation research [D]. Northwestern Polytechnical University, 2005. 